\title{
A 10 year follow up of 180 adults with bronchial asthma: factors important for the decline in lung function
}

\author{
Charlotte Suppli Ulrik, Vibeke Backer, Asger Dirksen
}

\begin{abstract}
Background Little is known about the factors that determine outcome in asthma. The purpose of this study was to describe the relation of various factors of potential importance to the rate of decline in lung function in adults with intrinsic and extrinsic asthma.

Methods Of 180 asthmatic patients, 143 (79\%) participated in a 10 year follow up examination. At the time of enrolment all patients underwent certain tests for asthma (case history, total IgE, skinprick tests, the radioallergosorbent test (RAST), histamine release from basophil leucocytes, and specific bronchial provocations). On the basis of these tests 94 patients had intrinsic asthma and 49 extrinsic asthma.
\end{abstract}

Results Patients with intrinsic asthma had an annual decline in $F V_{1}$ of $50 \mathrm{ml}$, whereas those with extrinsic asthma had a decline of $22.5 \mathrm{ml}$; the rate of decline of lung function increased with increasing age in both groups. An inverse relation between initial FEV, and decline in FEV (the "horse racing effect") was found for the patients with extrinsic asthma but not for the patients with intrinsic asthma. There was no relation between rate of decline in lung function and number of cigarettes smoked. A high degree of airway variability-that is, reversibility in $\mathrm{FEV}_{1}$ - at the time of enrolment was found to be associated with a steeper decline in lung function in patients with intrinsic asthma, whereas increasing degrees of obstruction (decreasing FEV $_{1} / \mathrm{VC}$ ratio at enrolment) and need for treatment with corticosteroids were associated with a more pronounced decline in $F E V_{1}$ in patients with extrinsic asthma.

Conclusions The rate of decline in lung function is greater in patients with intrinsic asthma than in patients with extrinsic asthma; the prognosis for intrinsic and extrinsic asthma is to some extent influenced by different factors, which suggests that the pathogenetic mechanisms underlying intrinsic and extrinsic asthma may differ.

Observations over the last decade suggest that the rate of decline in lung function in patients with asthma is greater than that in the nonasthmatic population, ${ }^{1}$ but these observations are unexplained. Whether the prognoses for intrinsic and extrinsic asthma are influenced by different factors is also unclear. Patients with extrinsic asthma have greater variability in airway obstruction than subjects with intrinsic asthma, who may have permanent bronchoconstriction. ${ }^{2}$ It has been suggested that continuous severe airway obstruction may be associated with an excessive decline in lung function, ${ }^{1}$ and that normalising lung function with optimal anti-asthma medication might prevent this exaggerated decline. ${ }^{3}$ These findings imply that decrease in lung function may be more pronounced in patients with intrinsic asthma than in those with extrinsic asthma, though this has not been ascertained.

Factors other than atopy could play a part in the increased decline in lung function. Blood eosinophilia has been found to be related to the severity of asthmatic symptoms, ${ }^{4}$ and smoking is known to increase the annual decline in lung function. ${ }^{5}$

The purpose of this study was to determine which factors are important for the prognosis in intrinsic and extrinsic asthma. We have determined the relation between rate of decline in lung function and type of asthma, sex, age, smoking habit, blood eosinophilia, response to a $\beta_{2}$ agonist, treatment with corticosteroids, duration of asthma, and degree of airway obstruction at the time of enrolment.

\section{Methods}

SUBJECTS

First examination

During 1976-9, 180 adults with asthma were referred to the allergy clinic and tested in the laboratory of respiratory physiology at the University Hospital in Copenhagen (Rigshospitalet). The diagnosis of asthma was a doctor's diagnosis made at the first examination at the allergy clinic, mainly on clinical grounds-that is, a combination of appropriate history, physical findings, and results of laboratory tests, including significant reversibility in forced expiratory volume in one second $\left(\mathrm{FEV}_{1}\right)$ with salbutamol. ${ }^{67}$

The patients were divided into two groupsthose with intrinsic asthma and those with extrinsic asthma. Patients were defined as having intrinsic asthma if they had normal concentrations of serum IgE and no evidence of extrinsic asthma from history, skin tests, radioallergosorbent tests (RAST), and-when the results of these were doubtful-histamine release from basophil leucocytes ${ }^{8}$ and specific 
bronchial provocation tests. ${ }^{910}$ The remaining subjects were defined as having extrinsic asthma.

\section{Follow up examination}

Names (in case of change) and addresses for all 180 patients were obtained from the civil registration list, and all patients were invited by letter to have a follow up examination. The follow up examination was performed about 10 (range 9-12, median 10) years after the first examination.

One hundred and forty three $(79 \%)$ of the 180 subjects participated in the follow up study in 1988. Of the 37 patients who did not participate, 22 replied to say that they could not take part because they had moved away from Copenhagen (more than $200 \mathrm{~km}$ ); and 15 patients refused to participate for various reasons when they were contacted by a second

- letter and by telephone. Informed consent was obtained from all participating subjects, and the study was approved by the ethics committee of Copenhagen.

On both occasions subjects were asked not to smoke for at least two hours before the examination. They were asked not to take theophylline or an antihistamine for at least 24 hours, astemizole for six weeks, or an oral $\beta_{2}$ agonist for 18 hours, and not to use an inhaled bronchodilator for six hours before the tests. They continued with any inhaled or oral corticosteroids they were using.

\section{THE TESTS}

First examination (table 1)

History All patients filled in a questionnaire about allergies ${ }^{4}$ and were interviewed about respiratory symptoms and duration of symptoms, use of antiasthma medication (drug and mean daily dose during last 12 months), and smoking habits (number of cigarettes a day and years of smoking) by one person (AD).

Skinprick tests Skinprick tests were performed with standard dilutions of allergens in $50 \%$ glycerol. ${ }^{4}$ The standard allergens used were: birch, timothy grass, mugwort, animal hair and dander (cat, horse, and dog), house dust allergen, house dust mite (Dermatophagoides farinae and $D$ pteronyssinus) and mould (Alternaria iridis, Cladosporium herbarum, and Mucor racemosus). Histamine hydrochloride, $1 \mathrm{mg} / \mathrm{ml}$ in $50 \%$ glycerol, was used as a positive reference for recording the skinprick test results; a negative reference was also included. The weal was read after 15-20 minutes. The area of the weal produced by each antigen was compared with the area of the histamine weal and regarded as positive if it was at least the same size as the histamine weal.

Total IgE Total serum IgE levels were determined by paper radioimmunosorbent test (PRIST, Pharmacia, Sweden). Values below $260 \mathrm{kU} / 1$ were regarded as normal. ${ }^{4}$

Blood eosinophil count The number of eosinophilic granulocytes in $3 \cdot 2 \mu \mathrm{l}$ was counted in a counting chamber." The blood eosinophil count was determined three times for each patient and the most abnormal result recorded. ${ }^{4}$
Table 1 Numbers of patients in whom each test was performed

\begin{tabular}{lcc}
\hline & \multicolumn{2}{l}{ No (\%) of patients } \\
\cline { 2 - 3 } Test & Enrolment & Follow up \\
\hline Case history & $180(100)$ & $143(100)$ \\
Skinprick test & $180(100)$ & \\
Total IgE & $180(100)$ & \\
Blood eosinophil count & $180(100)$ & \\
Radioallergosorbent test & $178(99)$ & \\
Specific bronchial provocation & $59(33)$ & \\
Histamine release from & $60(33)$ & \\
basophil leucocytes & $180(100)$ & $143(100)$ \\
Spirometry & & $129(90)$ \\
Diurnal variation in peak flow & $100(70)^{\star}$ \\
Bronchial histamine challenge test & & \\
\hline
\end{tabular}

$\star$ Thirty three $(23 \%)$ of the patients had a baseline FEV below 1.01 .

Radioallergosorbent test (RAST) Tests for allergen specific IgE (Al-RAST) were performed with the aluminium radioallergosorbent test kit according to the method of Weeke. ${ }^{12}$ The patients were screened by a modification of this, in which a mixture of four or five allergen extracts (a "pool") was used instead of one allergen only. The following pools were used: pollens (birch, timothy grass, mugwort, Artemisia vulgaris (mugwort), and Leucanthemum vulgare (oxeye daisy)), moulds (Alternaria iridis, Aspergillus fumigatus, Cladosporium herbarum, and Mucor racemosus); animals (horse, dog, cat, cow, and guinea pig); and "other" (house dust, $D$ farinae, $D$ pteronyssinus, and duck feathers). When the reaction to a pool was 10 sorbent units (SU) or above, each separate allergen within the pool was used for further RASTs; a reaction to one allergen of $20 \mathrm{SU}$ or more was regarded as a positive response. $^{4}$

Histamine release from basophil leucocytes This has been described in detail. ${ }^{8}$ The percentage of histamine released (out of the total histamine that could be released from the cells) was recorded. A characteristic curve was obtained by expressing the released histamine as a percentage of the total histamine (ordinate) with four dilutions-10-9, 10-7, 10-5, and 10$3-$ of the allergen extract (abscissa). A positive result was defined as release of $30 \%$ or more of the total cell content. ${ }^{4}$

Specific bronchial provocation One millilitre aqueous extract in phenol saline was nebulised to dryness with a Pari atomiser and a compressor (Inhalier Boy). Allergen extracts in concentrations that increased by a factor of 10 (from $10^{-6}$ to $10^{-2}$ ) were used. A positive reaction was defined as a fall in $\mathrm{FEV}_{1}$ of $20 \%$ or more. ${ }^{4}$ Bronchial provocation was carried out with one allergen only a day. Inhalation of phenol saline was included as a negative control.

Spirometric tests Forced expiratory volume in one second $\left(\mathrm{FEV}_{1}\right)$, peak expiratory flow $(\mathrm{PEF})$, and vital capacity (VC) were measured and the best of three technically acceptable readings was used for analysis. The tests were repeated 15 minutes after inhalation of $5 \mathrm{mg}$ of salbutamol. Reversibility of $F E V_{1}$ was calculated as $\left(\mathrm{FEV}_{1}\right.$ before- $\mathrm{FEV}_{1}$ after $) / \mathrm{FEV}_{1}$ before. Patients were said to show reversibility if $\mathrm{FEV}_{1}$ 
increased by at least $15 \%$ and showed an absolute increase of at least $200 \mathrm{ml} .{ }^{67}$ Reversibility for patients with an increase in $\mathrm{FEV}_{1}$ of less than $200 \mathrm{ml}$ was reported as zero. ${ }^{7}$

\section{Follow up examination (table 1)}

History All patients were interviewed by one person (CSU) about respiratory symptoms, medication requirements (recorded as at the first examination), smoking habits (recorded as at the first examination), and occupation.

Spirometric tests Measurements of $\mathrm{FEV}_{1}$, PEF, and VC were repeated at the second examination. The same equipment and technique were used at both examinations; at the second examination all spirometric tests were done by one person (CSU).

Diurnal variability in peak expiratory flow rate Subjects measured their PEF twice daily for a fortnight (best of three measurements). Diurnal variability in PEF was defined, according to Clark and Hetzel, ${ }^{1314}$ as (highest lowest measurement during the observation period)/mean of all measurements). Variability was defined as being present when it was at least $20 \%$. $^{1314}$

Histamine challenge tests A challenge test with histamine was carried out according to the protocol of Cockcroft and coworkers. ${ }^{15}$ The patient inhaled through a mouthpiece wearing a noseclip. Saline $(0.9 \%)$ and histamine were inhaled from a Wright nebuliser (output $0.14 \mathrm{ml} / \mathrm{min}$ ) with tidal breathing for two minutes. The $\mathrm{FEV}_{1}$ was measured one minute after each inhalation, and the highest of three recordings was used. The inhalations were continued after an interval of four minutes. After inhalation of saline the histamine concentration was doubled until a maximum of $8.0 \mathrm{mg} / \mathrm{ml}$ had been reached, or there was a decrease in $\mathrm{FEV}_{1}$ of at least $20 \%$ of the baseline (postsaline) value. The concentration of histamine that produced a $20 \%$ reduction in $\mathrm{FEV}_{1}\left(\mathrm{PC}_{20}\right)$ was read from the individual log-dose response curve. Bronchial responsiveness to histamine was measured only in subjects whose baseline $\mathrm{FEV}_{1}$ was greater than $1 \cdot 0 .{ }^{16}$ In patients with a recent respiratory infection the histamine challenge test was postponed for at least six weeks. $^{2}$

Table 2 Basic characteristics of the patients (medians with 95\% confidence intervals in parentheses)

\begin{tabular}{|c|c|c|c|}
\hline & $\begin{array}{l}\text { Intrinsic asthma } \\
(n=94)\end{array}$ & $\begin{array}{l}\text { Extrinsic asthma } \\
(n=49)\end{array}$ & $p$ \\
\hline $\begin{array}{l}\text { Sex (\% men) } \\
\text { Age (y) } \\
\text { Height (cm) } \\
\text { FEV }_{1}(1)\end{array}$ & $\begin{array}{l}36 \\
43 \cdot 5(39 \cdot 7 \text { to } 44 \cdot 5) \\
167\end{array}$ & $\begin{array}{l}43 \\
31 \cdot 0(27 \cdot 9 \text { to } 34 \cdot 8) \\
169\end{array}$ & $\begin{array}{l}\text { (NS) } \\
<0.001 \\
\text { (NS) }\end{array}$ \\
\hline $\begin{array}{l}\text { Enrolment } \\
\text { Follow up }\end{array}$ & $\begin{array}{l}2.30(2.20 \text { to } 2.45) \\
1.80(1.65 \text { to } 1.90)\end{array}$ & $\begin{array}{l}2.60(2.40 \text { to } 2.90) \\
2.60(2.30 \text { to } 2.70)\end{array}$ & $\begin{array}{l}0.006 \\
<0.00001\end{array}$ \\
\hline $\begin{array}{l}\text { FEV }_{1} \text { (\% pred) } \\
\text { Enrolment } \\
\text { Follow up }\end{array}$ & $\begin{array}{l}72.8(69.3 \text { to } 76.4) \\
60.7(56.3 \text { to } 65.0)\end{array}$ & $\begin{array}{l}73 \cdot 6(68 \cdot 0 \text { to } 79 \cdot 2) \\
72 \cdot 8(68 \cdot 7 \text { to } 79 \cdot 1)\end{array}$ & $\begin{array}{l}\text { (NS) } \\
0.00002\end{array}$ \\
\hline $\begin{array}{l}\text { FEV }_{1} \text { (\% reversibility) } \\
\text { Enrolment }_{\text {Follow up }} \\
\text { B eosinophils (mia/l) } \\
\text { Duration of asthma (y) }\end{array}$ & $\begin{array}{c}26.0(20.7 \text { to } 31.3) \\
20.3(14.7 \text { to } 25.9) \\
0.67(0.57 \text { to } 0.81) \\
23.3(20.5 \text { to } 26.0)\end{array}$ & $\begin{array}{l}16.4(9.9 \text { to } 22.8) \\
21.1(14.8 \text { to } 27.3) \\
0.77(0.62 \text { to } 0.97) \\
22.7(19.5 \text { to } 25.8)\end{array}$ & $\begin{array}{l}0.0002 \\
\text { (NS) } \\
\text { (NS) } \\
\text { (NS) }\end{array}$ \\
\hline
\end{tabular}

DATA ANALYSIS

Predicted values for $\mathrm{FEV}_{1}, \mathrm{PEF}$, and VC were calculated by using the regression of Quanjer $e t$ al. ${ }^{17}$ Apart from data on reversibility, all analyses were made from the spirometric recordings made after inhalation of salbutamol. Data are reported, unless stated otherwise, as median values and $95 \%$ confidence intervals (CI). ${ }^{18}$ The Mann-Whitney rank test was used to compare the two groups. Decline in $\mathrm{FEV}_{1}$ was calculated as the difference in measured $\mathrm{FEV}_{1}$ between the two examinations divided by the number of years of follow up. Factors of possible importance for the decline in $\mathrm{FEV}_{1}$ were entered into a multiple regression model and non-significant variables were deleted by backward elimination to determine those associated with decline in $\mathrm{FEV}_{1}$. The data were analysed with type of asthma as an independent variable in the regression model and with interaction terms between type of asthma and other independent variables to test for differences in the influence of independent variables on patients with intrinsic and extrinsic asthma.

\section{Results}

Of the 143 patients, 94 had intrinsic asthma and 49 extrinsic asthma. Their median age differed, being 43.5 and 31 years respectively at the time of enrolment ( $p<0.001$ ) (table 2). At the first examination the median $\mathrm{FEV}_{1}$ as a percentage of the predicted value $\left(\mathrm{FEV}_{1} \%\right.$ pred) was similar in the patients with intrinsic $(73 \%)$ and extrinsic ( $74 \%$ ) asthma (table 2 ); by 1988 the median $\mathrm{FEV}_{1} \%$ pred differed, being 61 (CI 56 to 65) and 74 (69 to 79) respectively $(p=0.0002)$. At the time of enrolment the patients with intrinsic asthma had significantly greater reversibility in $\mathrm{FEV}_{1}(\%)$ than the patients with extrinsic asthma (26 (CI 21 to 31$)$ and 16 (CI 10 to 23). There was no difference in reversibility in $\mathrm{FEV}_{1}(\%)$ at the follow up examination (20 (CI 15 to 27) and 21 (CI 15 to $27) ; \mathrm{p}>0.05)$ or in diurnal variability ( 32 (CI 26 to 38 ) and 36 (CI 31 to 46)) between the two groups. There was also no difference in median $\mathrm{PC}_{20}$ between the two groups in 1988, the values being 1.05 (CI 1.5 to 2.9) and 1.3 (CI 1.6 to $4 \cdot 8) \mathrm{mg} / \mathrm{ml}$.

CHANGE IN FEV 1

Patients with intrinsic asthma had a greater median decrease in $\mathrm{FEV}_{1}(50$ (CI -45 to -62$)$ $\mathrm{ml} / \mathrm{y})$ than those with extrinsic asthma (22.5 $(\mathrm{CI}-1$ to -32$) \mathrm{ml} / \mathrm{y} ; \mathrm{p}<0.0001)$. According to Quanjer ${ }^{17}$ the expected annual decline in $\mathrm{FEV}_{1}$ is $29 \mathrm{ml}$ for men and $25 \mathrm{ml}$ for women; so the $\mathrm{FEV}_{1} \%$ pred was almost unchanged for the patients with extrinsic asthma. Twenty eight $(20 \%)$ of the patients were current smokers $(20$ with intrinsic asthma and eight with extrinsic asthma) and 24 (17\%) were former smokers (18 and five respectively). There was no difference in number of pack years between the patients with intrinsic asthma (median 4.6 , CI 2.9 to 6.4 ) and those with extrinsic asthma (median 4.7 , CI 1.8 to $6.8 ; p=0.43$ ). Patients with intrinsic asthma were more likely to be receiving corticosteroids $(62,66 \%)$ than patients with extrinsic asthma $(23,47 \% ; p<0.01)$. 
Table 3 Factors important for the decline in FEV in patients with intrinsic and extrinsic asthma

\begin{tabular}{|c|c|c|c|c|c|c|}
\hline \multirow[b]{2}{*}{$x$} & \multicolumn{3}{|c|}{ Intrinsic asthma } & \multicolumn{3}{|c|}{ Extrinsic asthma } \\
\hline & Coefficient & Confidence interval & $p$ & Coefficient & Confidence interval & $p$ \\
\hline Age & -0.0102 & -0.0177 to -0.0027 & 0.008 & -0.0156 & -0.0259 to -0.0053 & 0.003 \\
\hline $\mathrm{FEV}_{1} \star$ & $-0 \cdot 1618$ & -0.3416 to & (NS) & $-0 \cdot 2266$ & -0.3848 to -0.0684 & 0.005 \\
\hline $\mathrm{FEV}_{1} / \mathrm{VC}^{\star}$ & -0.0520 & -0.7536 to & (NS) & -1.5837 & -2.5481 to -0.6193 & 0.001 \\
\hline $\mathrm{FEV}_{1}$ reversibility (1)* & -0.3937 & -0.6887 to -0.0987 & 0.009 & -0.1541 & -0.5889 to $\quad 0.2807$ & (NS) \\
\hline B eosinophils $(\mathrm{mia} / \mathrm{l})^{\star}$ & 0.0959 & 0.0256 to & 0.007 & -0.0243 & $-0 \cdot 1180$ to & (NS) \\
\hline Corticosteroids (mg/day) & -0.0054 & -0.0220 to & (NS) & -0.0364 & -0.0599 to -0.0129 & 0.002 \\
\hline
\end{tabular}

^At enrolment.

FACTORS AFFECTING DECLINE IN FEV

Multiple regression analysis showed increasing age to be associated with a steeper decline in $\mathrm{FEV}_{1}$ in patients with both intrinsic and extrinsic asthma ( $p<0.008$ ) (table 3 ); no significant relation was found between rate of decline in $\mathrm{FEV}_{1}$ and sex, smoking habits, or duration of asthma.

In patients with intrinsic asthma decline in $\mathrm{FEV}_{1}$ was related to reversibility in $\mathrm{FEV}_{1}$ at the time of enrolment ( $p=0.009$ ) and inversely with blood eosinophil count (table 3). It was not related significantly to $\mathrm{FEV}_{1}$ or $\mathrm{FEV}_{1} / \mathrm{VC}$ at the first examination (table 3 ).

For the patients with extrinsic asthma decline in $\mathrm{FEV}_{1}$ was associated inversely with $\mathrm{FEV}_{1}$ and $\mathrm{FEV}_{1} / \mathrm{VC}$ at the time of enrolment ( $p=0.005$ and 0.001 respectively) and with increasing need for treatment with corticosteroids ( $p=0.002)$; it was not related to degree of variability in $\mathrm{FEV}_{1}$ (reversibility) or to blood eosinophil count at the time of enrolment (table 3).

The two way interaction term between corticosteroids (mg/day), blood eosinophil count, and type of asthma in the multiple regression model was non-significant for both types of asthma.

\section{Discussion}

There is no generally accepted definition of asthma ${ }^{19}$ and no single definition of intrinsic asthma. This may in part be due to difficulties in separating patients with intrinsic asthma from patients with non-asthmatic chronic obstructive lung disease. ${ }^{20}$ In this study the diagnosis of asthma was based on appropriate history, physical findings, and results of laboratory tests (including lung function tests). Smoking, especially cigarette smoking, is generally agreed to be the single most important factor for the development of chronic obstructive lung disease. ${ }^{521}$ Only $21 \%$ of the patients with intrinsic asthma in the present study were current smokers and $20 \%$ were ex-smokers. At the time of enrolment in the study the patients with intrinsic asthma showed greater reversibility in $\mathrm{FEV}_{1}$ than the patients with extrinsic asthma. We do not therefore think that the differences we found between intrinsic and extrinsic asthma are due to inclusion of patients with chronic obstructive lung disease among our patients with intrinsic asthma.

The patients in this study were selected from patients attending clinics, who might therefore have had more severe asthma or might have been more difficult to treat than patients with asthma in the general population. This is supported by the relatively high proportion of patients with intrinsic asthma. At the time of follow up only half the patients were attending a hospital, the others now attending their general practitioner. Although the patients in this study might not be representative of the asthmatic population at large, our findings provide information on the natural history of asthma.

Our study shows that an exaggerated decline in lung function occurs, especially among older patients with asthma. Fletcher $e t$ al $^{22}$ described the "horse racing effect," which is a relation between the "level" of the $\mathrm{FEV}_{1}$ and its rate of decline over time. In our study the expected "horse racing effect" was found for the patients with extrinsic asthma, but not among those with intrinsic asthma. These findings suggest that at least some of the patients with intrinsic asthma have an accelerated decline in $\mathrm{FEV}_{1}$ with increasing age even if their lung function was within the normal range initially. In the patients with intrinsic asthma we found that a high degree of reversibility at the time of enrolment was associated with a steeper decline in lung function over the following 10 years. This is in keeping with the findings of Vollmer et $a l,{ }^{23}$ who found that the response to an inhaled bronchodilator correlated with the rate of decline of $\mathrm{FEV}_{1}$ only in subjects classified as having bronchial hyperresponsiveness (defined as a substantial response to inhaled isoproterenol). Our findings perhaps suggest that patients with intrinsic asthma at least should be treated so that the baseline lung function is also kept as near normal as possible. ${ }^{24}$

We were unable to find a significant relation between duration of asthma and decline in lung function, though the results in both groups suggest that longer duration may be associated with increasing decline in lung function ( $p=0.11$ and 0.12 respectively; data not shown); the finding may have been nonsignificant because other factors, such as age, $\mathrm{FEV}_{1}$ at enrolment, degree of obstruction, and reversibility were more important in determining the decline in $\mathrm{FEV}_{1}$.

As smoking is the most important factor for the development and prognosis of irreversible obstructive lung disease ${ }^{521}$ patients with 
asthma who smoke would be expected to have a steeper decline in lung function than patients who do not. ${ }^{25}$ Individual susceptibility to the effects of cigarette smoke on lung function is highly variable, ${ }^{26}$ however, and a similar spectrum might be expected in patients with asthma who smoke. We did not find an effect of cigarette smoking in addition to the effect of asthma, probably because the number of smokers was small $(20 \%)$, and they had smoked relatively modest amounts of tobacco. Some of the smokers, however, had a very steep decline in $\mathrm{FEV}_{1}$ (over $100 \mathrm{ml} /$ year; data not shown), suggesting that the decline in $\mathrm{FEV}_{1}$ in at least some individuals with asthma may be further accelerated by regular smoking even though no effect was seen overall.

Peat et $a l^{1}$ found a significant correlation between the rate of decline of $\mathrm{FEV}_{1}$ and bronchial hyperresponsiveness in a population study. Unfortunately our patients were not tested for bronchial hyperresponsiveness at the first examination. Our finding that reversibility in $\mathrm{FEV}_{1}$ (at the first examination) was related to decline in lung function in patients with intrinsic asthma is in keeping with this because Ryan et $a l^{28}$ found a close relation between nonspecific bronchial responsiveness to histamine and change in flow rates after a bronchodilator.

Daily symptoms of asthma (in contrast to weekly or monthly symptoms) have been shown to relate to blood eosinophil counts. ${ }^{4}$ In our study we found that higher eosinophil counts in patients with intrinsic asthma were associated with lower rates of decline in $\mathrm{FEV}_{1}$. The most probable explanation for this is that $66 \%$ of the patients with intrinsic asthma were treated with corticosteroids, which are known to lower the eosinophil count. ${ }^{29}$ For the patients with extrinsic asthma we found a direct and significant relation between treatment with corticosteroids and decline in lung function.

We conclude that the prognosis with regard to decline in lung function is worse for patients with intrinsic asthma than for patients with extrinsic asthma. The fall in $\mathrm{FEV}_{1}$ in patients with intrinsic asthma depended primarily on the age of the patient, whereas the fall in FEV in patients with extrinsic asthma was also influenced by the initial level of $F E V_{1}$ and the $\mathrm{FEV}_{1} / \mathrm{VC}$ at the time of enrolment. We conclude that the prognosis for intrinsic and extrinsic asthma are to some extent influenced by different factors, and therefore that the pathogenetic mechanisms behind intrinsic and extrinsic asthma may differ.

1 Peat JK, Woolcock AJ, Cullen K. Rate of decline of lung function in subjects with asthma. Eur $J$ Respir Dis 1987;70:171-9.
2 Cockcroft DW. Modulation of airway hyperresponsiveness. Ann Allergy 1988;60:465-71.

3 Woolcock AJ, Yan K, Salome CM. Effect of therapy on bronchial hyperesponsiveness in the long-term management of asthma. Clin Allergy 1988;18:165-76.

4 Dirksen A. Clinical vs. paraclinical data in allergy. Dan Med Bull 1982;29(suppl 5):5-72.

5 Lange P, Groth S, Nyboe J, Mortensen J, Appleyard H Jensen $\mathrm{G}$, et al. The effects of smoking habits on the decline

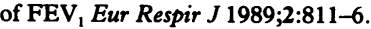

6 Ries AK. Response to bronchodilators. In: Clausen JL, ed. Pulmonary function testing: guidelines and controversies. New York: Academic Press 1982;215-21.

7 Viljanen A. Reference values for spirometric, pulmonary diffusing capacity and body plethysmographic studies. Scand J Clin Invest 1982;42 suppl 159:1-50.

8 Skov PS, Permin H, Malling H-J. Quantitative and qualitative estimations of IgE bound to basophil leucocytes from hay fever patients. Scand $J$ Immunol 1977;6:1021-8.

9 Koch C, Andersen P, Hertz JB, Høiby N, Kappelgaard E, Møller NE, et al. Studies on hypersensitivity to bacteria antigens in intrinsic asthma. Allergy 1982;37:191-201.

10 Irani FA, Jones NL, Gent M, Newhouse MT. Evaluation of disodium cromoglycate in intrinsic and extrinsic asthma. Am Rev Respir Dis 1972;106:179-85.

11 Urhband $\mathrm{H}$. Tælling af cirkulerende eosinofile celler tællekammer [in Danish, summary in English]. Ugeskr Laeger 1952;114:385-93.

12 Weeke B. Aluminium hydroxide absorbed allergens used in a modified RAST (AI-RAST) [abstract]. Allergol Immunopathol 1977;4:333.

13 Hetzel MR, Clark TJH. Comparison of normal and asth matic circadian rhythms in peak expiratory flow rate. Thorax 1980;35:732-8.

14 Clark TJH, Hetzel MR. Diurnal variation of asthma. $\mathrm{Br} J$ Dis Chest 1977;71:87-92.

15 Cockcroft DW, Killian DN, Melleon JJA, Hargreave FE Bronchial reactivity to inhaled histamine: a method and clinical survey. Clin Allergy 1977;7:235-43.

16 Hargreave FE, Ryan G, Thomson NC, O'Byrne PM, Latimer K, Juniper EF, et al. Bronchial responsiveness to histamine or methacholine in asthma. Measurement and clinical significance. J Allergy Clin Immunol 1981;68: 347-55.

17 Quanjer $\mathrm{Ph}$, ed. Standardized lung function testing. Bull Eur Physiopathol Respir 1983;19(suppl 5):7-10.

18 Johnson DB, Mizoguchi T. Selecting the Kth element in $\mathrm{X}+\mathrm{Y}$ and $\mathrm{X} 1+\mathrm{X} 2+\ldots \mathrm{Xm}$. Siamese Journal of Computing 1978;7:147-53.

19 Gross NJ. What is this thing called love?-or, defining asthma. Am Rev Respir Dis 1980;124:203-4.

20 American Thoracic Society. Standards for the diagnosis and care of patients with chronic obstructive pulmonary disease (COPD) and asthma. Am Rev Respir Dis 1987; 136:225-44.

21 Oswald NC, Medvei VC. Chronic bronchitis (the effect of cigarette smoking). Lancet 1955;2:843-7.

22 Fletcher CM, Peto R, Tinker CM, Speizer FE. The natura history of chronic bronchitis and emphysema. Oxford: Oxford University Press 1976;70-85.

23 Vollmer WM, Johnson LR, Buist AS Relationship of response to a bronchodilator and decline in forced expiratory volume in one second in population studies. expiratory volume in one second in pop
Am Rev Respir Dis 1985;132:1186-93.

24 Woolcock AJ. Inhaled drugs in the prevention of asthma. Chest 1985;87:94-8S.

25 Fennerty AG, Banks J, Ebden P, Bevan C. The effect of cigarette withdrawal on asthmatics who smoke. Eur $J$ Respir Dis 1987;71:395-9.

26 Kuperman AS, Riker JB. The variable effect of smoking on pulmonary function. Chest 1973;63:655-60.

27 Barter CE, Campbell AH. Relationship of constitutional factors and cigarette smoking to decrease in 1-second forced expiratory volume. Am Rev Respir Dis 1976; 113:305-14.

28 Ryan G, Latimer KM, Dolovich J, Hargreave FE. Bronchial responsiveness to histamine: relationship to diurnal variation of peak flow rate, improvement after bronchodilator, tion of peak flow rate, improvement after bron

29 Horn BR, Robin ED, Theodore J, van Kessel A. Total eosinophil counts in the management of bronchial asthma. N Eng J Med 1975;292:1154-5. 